\title{
PENGEMBANGAN PRODUK KOPI PREMIUM DENGAN METODE QFD SEBAGAI PRODUK UNGGULAN KELOMPOK TANI KOPI MAKMUR ABADI
}

\section{Development of Premium Coffee Product Using QFD Method as The Leading Product of Makmur Abadi Coffee Farmers Group}

\author{
Jaya Mahar Maligan ${ }^{1,3 *}$, Muhammad Aditya Dwisaputra ${ }^{1}$, Siti Asmaul Mustaniroh² \\ 1) Jurusan Teknologi Hasil Pertanian, FTP Universitas Brawijaya \\ 2) Jurusan Teknologi Industri Pertanian, FTP Universitas Brawijaya \\ 3) Pusat Studi Pengembangan Pangan Lokal, Universitas Brawijaya \\ JI.Veteran, Malang 65145 \\ *Penulis Korespondensi, email: maharajay@gmail.com
}

\begin{abstract}
ABSTRAK
Kelompok Tani Kopi Makmur Abadi (KTKMA) merupakan salah satu produsen kopi yang berada di Jawa Timur dengan produk kopi bubuk Tri Tunggal. Permasalahan yang dihadapi adalah kualitas bubuk kopi yang cukup rendah. Oleh karena itu, diperlukan langkah pengembangan produk kopi baru dengan kualitas lebih baik yang dilabeli sebagai kopi premium. QFD merupakan sebuah metode yang digunakan untuk menerjemahkan Voice of Customer (VoC) menjadi produk baru yang dapat memenuhi kebutuhan konsumen. Variabel kualitas kopi yang digunakan adalah fragrance/aroma, flavor, aftertaste, salt/acid, bitter/sweet, mouthfeel, balance, uniform cups, clean cups, dan overall. Responden penelitian berjumlah 96 orang untuk mengisi kuesioner $\mathrm{VoC}$ dan 10 orang sebagai panelis terlatih. Melalui analisis dengan metode QFD diketahui bahwa untuk memenuhi kebutuhan konsumen, KTKMA perlu melakukan pelatihan operator sesuai instruksi kerja, kontrol pascapanen buah dan biji kopi, kontrol tahap sortasi biji kopi, kontrol konsistensi suhu dan durasi penyangraian, dan kontrol durasi pendinginan biji kopi.
\end{abstract}

Kata Kunci: Kebutuhan, Konsumen, Kopi premium, QFD

\begin{abstract}
One of the producers of coffee products in East Java is the Makmur Abadi Coffee Farmers Group (MACFG). However, the problem is that the Tri Tunggal ground coffee product which has been produced was in low quality. It is necessary to develop new and better quality coffee products. QFD is a method used to translate Voice of Customer (VoC) into new products that can meet the needs of consumers. Variables used are fragrance/aroma, flavor, aftertaste, salt/acid, bitter/sweet, mouthfeel, balance, uniform cups, clean cups, and overall. Research respondents numbered 96 people to fill out the VoC questionnaire and 10 people as trained panelists. With QFD method, it is known that to meet customers needs, MACFG needs to conduct operator training in accordance with work instructions, control in several stage including postharvest, sorting, temperature consistency and roasting duration and cooling duration of coffee beans.
\end{abstract}

Keywords: Coffee, Customer, Needs, QFD

\section{PENDAHULUAN}

Trend minum kopi semakin meningkat pada beberapa tahun belakangan ini. Peningkatan ini disebabkan oleh jumlah industri pengolahan kopi di Indonesia yang semakin 
meningkat pula. Kopi sudah menjadi bagian dari gaya hidup sebagian besar masyarakat Indonesia (Trinafianita dan Widyaningsih, 2018). Salah satu produsen produk kopi bubuk yang berada di wilayah Jawa Timur adalah Kelompok Tani Kopi Makmur Abadi (KTKMA). Kelompok tani tersebut merupakan salah satu unit usaha yang bergerak di bidang pengolahan biji kopi skala kecil dengan mesin semi-otomatis yang berlokasi di Dusun Sumberdadi, Desa Kandangan, Kecamatan Pesanggaran, Kabupaten Banyuwangi. Kelompok tani kopi ini mengelola lahan kebun kopi jenis robusta milik pribadi yang hasilnya diambil sebagai bahan baku untuk dijadikan produk kopi bubuk dengan merk Tri Tunggal. Keunikan dari merek kopi tesebut adalah komposisi produk yang terdiri dari campuran biji jagung dan biji kopi robusta dengan perbandingan 3:1 (porsi biji jagung lebih banyak). Salah satu alasan penambahan biji jagung dalam produksi kopi bubuknya adalah untuk menambah bobot produk kopi bubuk yang dihasilkan (Syah, Yusmanizar, dan Maulana, 2013). Namun, menurut survei pendahuluan yang telah dilakukan, produk kopi bubuk Tri Tunggal yang telah diproduksi selama ini masih memiliki aroma yang lemah, rasa kopi yang kalah oleh rasa jagung, tidak berasa pahit khas kopi, berasa gosong, dan sangat tidak nyaman di tenggorokan. Beberapa atribut tersebut tentunya akan mengurangi minat konsumen terhadap produk kopi bubuk yang dihasilkan oleh KTKMA.

Solusi yang dapat ditawarkan adalah dengan melakukan perbaikan formula produk kopi dan alur proses produksi. Maka dari itu, diperlukan langkah pengembangan produk kopi baru dengan kualitas lebih baik atau dapat disebut juga dengan produk kopi premium. Hadirnya produk premium tersebut akan memberikan kesan bahwa kopi premium yang diproduksi memiliki kualitas yang tinggi dan bertindak sebagai diferensiasi produk yang dapat menjangkau target pasar lebih luas. Untuk melakukan pengembangan produk berdasarkan kebutuhan konsumen, salah satu metode analisis yang cocok digunakan adalah Quality Function Deployment (QFD). Metode QFD merupakan metode yang umum digunakan untuk meningkatkan kualitas berbagai jenis produk, material, perangkat, dan jasa (Jensen, 2017). Metode QFD telah diaplikasikan pada beberapa produk kopi bubuk diantaranya peningkatan kualitas kopi bubuk merk "Gunung ljen Robusta" (Retnowati, 2012), pengembangan produk "Kopiku Ae" (Nevita dan Andi, 2017) dan pengendalian kualitas kopi bubuk "Banyuatis Reguler" (Andriani, 2017). Metode QFD ini dilakukan dengan cara memahami kebutuhan konsumen yang kemudian dihubungkan dengan ketentuan teknis untuk menghasilkan barang dan jasa yang diinginkan. Diharapkan dengan adanya langkah pengembangan produk ini dapat menghasilkan produk kopi premium dengan kualitas yang sesuai dengan kebutuhan konsumen.

\section{BAHAN DAN METODE}

\section{Bahan}

Alat

Bahan yang digunakan adalah biji kopi yang dihasilkan KTKMA

Alat yang digunakan adalah mesin sangrai dan giling kopi, teko leher angsa, timbangan meja, cangkir kopi dan sendok.

\section{Desain Penelitian}

Penelitian yang dilakukan adalah penelitian eksperimental dengan menggunakan metode QFD untuk pengembangan produk kopi premium.

\section{Prosedur Penelitian}

Penelitian diawali dengan melakukan survei pendahuluan yang bertempat di KTKMA. Kemudian dilanjutkan dengan mengidentifikasi masalah dan melakukan studi literatur untuk menelusuri cara dalam menyelesaikan masalah yang ada. Batasan masalah dalam penelitian ini adalah pengembangan produk kopi premium hanya dilakukan berdasarkan dimensi kualitas produk, yaitu kinerja produk (performance). 


\section{Identifikasi Variabel}

Variabel yang digunakan dalam penelitian ini adalah karakteristik produk kopi berdasarkan atribut standar kopi robusta yang telah ditetapkan oleh Uganda Coffee Development Authority (UCDA). Variabel tersebut dijadikan acuan dalam penilaian produk kopi premium oleh panelis survei. Variabel yang digunakan, antara lain: fragrance/aroma, flavor, aftertaste, salt/acid, bitter/sweet, mouthfeel, balance, uniform cups, clean cups, and overall (UCDA, 2010).

\section{Penentuan Sampel}

Teknik pengambilan sampel responden kuesioner VoC yang digunakan adalah teknik non-probability sampling dengan purposive sampling sehingga tidak memberikan peluang atau kesempatan yang sama bagi setiap unsur atau anggota populasi untuk dipilih menjadi sampel karena harus memenuhi pertimbangan tertentu atau seleksi khusus (Siyoto dan Sodik, 2015). Dalam penelitian ini, responden yang dituju adalah pria dan wanita yang gemar mengonsumsi produk kopi minimal empat kali dalam satu pekan. Jumlah sampel responden diperoleh dengan menggunakan bantuan rumus Linear Time Function (LTF). Penggunaan rumus tersebut diperlukan karena kemungkinan populasi yang sesuai dengan kriteria berjumlah sangat besar sehingga tidak dapat diketahui dengan pasti jumlah sampel yang terlibat (Umar, 2000). Berdasarkan rumus LTF (Putri , Effendi, dan Effendi 2015), diperoleh jumlah sampel responden kuesioner VoC sebanyak 96 orang. Sementara itu, diperlukan juga 10 orang panelis survei dari kalangan profesi barista untuk menilai kepuasan produk kopi.

\section{Uji Validitas dan Reliabilitas}

Dalam penelitian ini, uji validitas dan reliabilitas dilakukan dengan menggunakan bantuan aplikasi SPSS 25 . Uji validitas digunakan untuk mengetahui kelayakan butir-butir pertanyaan di kuesioner yang akan digunakan dalam mendefinisikan suatu variabel (Umar, 2000). Sementara itu, uji reliabilitas diperlukan untuk menunjukkan konsistensi alat ukur saat mengukur suatu gejala yang sama (Gumilar, 2007).

\section{Tahapan Penelitian}

\section{Pembuatan prototipe kopi premium}

Proses pembuatan prototipe kopi premium dilakukan di KTKMA. Prototipe kopi premium dibuat dengan formula $100 \%$ biji kopi robusta. Pemilihan formula tersebut didasarkan oleh hasil survei pendahuluan yang menunjukkan bahwa produk kopi bubuk Tri Tunggal yang menggunakan campuran jagung dinilai tidak memiliki aroma dan rasa khas kopi, melainkan didominasi oleh cita rasa jagung. Proses pembuatan prototipe diawali dengan pemilihan biji kopi robusta, penyortasian biji kopi, penyangraian dengan suhu $130^{\circ} \mathrm{C}$ selama 50 menit hingga mencapai profil dark roast, dan dilanjutkan dengan pendinginan biji kopi serta pengemasan.

\section{Fase I QFD: Product planning}

Fase pertama dilakukan dengan menyusun House of Quality (HoQ). Penyusunan HoQ harus dilakukan dengan cermat dan teliti karena berpengaruh terhadap fase selanjutnya. Untuk menyusun $\mathrm{HoQ}$ terdapat beberapa matriks yang perlu dibuat, antara lain (Putri $\mathrm{R}$, Effendi, dan Effendi, 2015) matriks kebutuhan konsumen, matriks perencanaan, matriks respon teknis, matriks, matriks hubungan, matriks teknis, dan matriks korelasi teknis.

\section{Fase II QFD: Product design}

Di fase yang kedua, persyaratan teknis yang telah diperoleh dari fase pertama diterjemahkan menjadi spesifikasi komponen desain produk kopi premium untuk memenuhi kebutuhan konsumen (Patro dan Prasad, 2013).

\section{Fase III QFD: Process planning}

Dalam fase ketiga, spesifikasi kunci komponen desain produk kopi premium yang telah ditentukan di fase kedua diterjemahkan menjadi rencana proses produksi untuk memenuhi spesifikasi tersebut (Mehrjerdi, 2010).

\section{Fase IV QFD: Production planning}


Terakhir adalah fase yang keempat di mana rencana proses terpilih dari fase ketiga diterjemahkan menjadi persyaratan produksi dalam bentuk instruksi kerja, perencanaan kontrol, dan persyaratan lain yang dibutuhkan untuk memastikan kualitas komponen kunci dan proses kunci produksi tetap terjaga (Mehrjerdi, 2010).

Metode

Metode penelitian yang digunakan adalah QFD yang meliputi 4 fase:product planning, product design, process planning dan production planning (Putri R, Effendi, dan Effendi, 2015).

\section{Prosedur Analisis}

Analisis data menggunakan metode deskriptif.

\section{HASIL DAN PEMBAHASAN}

\section{Fase I: Product Planning}

\subsection{Matriks kebutuhan konsumen}

Perolehan data untuk matriks ini berasal dari kuesioner Voice of Customer (VoC) bagian pertanyaan terbuka. Dalam bagian tersebut, sebanyak 96 responden diminta untuk menuliskan dengan lengkap harapan untuk produk kopi premium. Kesimpulan kebutuhan konsumen dapat dilihat di Tabel 1.

Tabel 1. Kebutuhan Konsumen

\begin{tabular}{cll}
\hline & \multicolumn{2}{c}{ Kebutuhan Konsumen } \\
\hline Primer & \multicolumn{1}{c}{ Sekunder } & \multicolumn{1}{c}{ Tersier } \\
\hline & Fragrance/Aroma & Aroma khas kopi yang kuat \\
& Flavor & Sensasi aroma cokelat \\
& Aftertaste & Khas kopi, tidak terlalu pahit \\
& Salt/Acid & Bertahan lama \\
Kinerja produk & Mouthfeel & Tingkat keasaman rendah \\
& Bitter/Sweet & Tekstur tebal \\
& Clean Cups & Tingkat kemanisan rendah \\
& Uniform cups & Karakter rasa bersih \\
& Balance & Konsisten di setiap penyajian \\
& Overall & Kombinasi seimbang \\
& & Terasa nikmat \\
\hline
\end{tabular}

\subsection{Matriks perencanaan}

Tahap yang kedua dalam menyusun House of Quality ( $\mathrm{HoQ})$ adalah dengan membuat matriks perencanaan. Matriks ini berisi hasil riset pasar yang telah dilakukan untuk pengembangan produk kopi premium. Matriks perencanaan terdiri dari beberapa bagian penyusun, antara lain:

\subsubsection{Tingkat Kepentingan Konsumen}

Hasil pengolahan data mengenai tingkat kepentingan suatu atribut kopi premium bagi konsumen dapat dilihat di Tabel 2.

Tabel 2. Kepentingan Konsumen

\begin{tabular}{clccc}
\hline No. & \multicolumn{1}{c}{ Atribut } & $\begin{array}{c}\text { Skala } \\
\text { Kepentingan }\end{array}$ & $\begin{array}{c}\text { Persentase } \\
(\%)\end{array}$ & Keterangan \\
\hline 1 & Overall & 5 & 57.3 & Sangat penting \\
2 & Flavor & 5 & 56.3 & Sangat penting \\
3 & Uniform Cups & 5 & 51 & Sangat penting \\
4 & Clean Cups & 5 & 47.9 & Sangat penting \\
5 & Balance & 5 & 46.9 & Sangat penting \\
6 & Fragrance/Aroma & 5 & 42.7 & Sangat penting \\
7 & Mouthfeel & 4 & 54.2 & Penting \\
\hline
\end{tabular}




\begin{tabular}{clccc}
\hline 8 & Bitter/Sweet & 4 & 50 & Penting \\
9 & Aftertaste & 3 & 38.5 & Cukup penting \\
10 & Salt/Acid & 3 & 37.5 & Cukup penting \\
\hline
\end{tabular}

\subsubsection{Tingkat Kepuasan Konsumen pada Prototipe Produk}

Hasil pengolahan data mengenai tingkat kepuasan konsumen terhadap prototipe kopi premium dapat dilihat di Tabel 3.

Tabel 3. Kepuasan Konsumen

\begin{tabular}{clccl}
\hline No. & \multicolumn{1}{c}{ Atribut } & $\begin{array}{c}\text { Skala } \\
\text { Kepuasan }\end{array}$ & $\begin{array}{c}\text { Persentase } \\
(\%)\end{array}$ & Keterangan \\
\hline 1 & Bitter/Sweet & 5 & 60 & Sangat puas \\
2 & Uniform Cups & 5 & 60 & Sangat puas \\
3 & Clean Cups & 5 & 50 & Sangat puas \\
4 & Flavor & 2 & 70 & Tidak puas \\
5 & Overall & 2 & 70 & Tidak puas \\
6 & Balance & 2 & 40 & Tidak puas \\
7 & Mouthfeel & 2 & 40 & Tidak puas \\
8 & Fragrance/Aroma & 2 & 40 & Tidak puas \\
9 & Salt/Acid & 1 & 70 & Sangat tidak puas \\
10 & Aftertaste & 1 & 40 & Sangat tidak puas \\
\hline
\end{tabular}

\subsubsection{Tingkat Kepuasan Konsumen pada Produk Pesaing}

Hasil pengolahan data mengenai tingkat kepuasan konsumen terhadap produk kopi pesaing dapat dilihat di Tabel 4.

Tabel 4. Kepuasan Konsumen

\begin{tabular}{clccc}
\hline No. & \multicolumn{1}{c}{ Atribut } & $\begin{array}{c}\text { Skala } \\
\text { Kepuasan }\end{array}$ & $\begin{array}{c}\text { Persentase } \\
(\%)\end{array}$ & Keterangan \\
\hline 1 & Clean Cups & 5 & 90 & Sangat puas \\
2 & Uniform Cups & 5 & 80 & Sangat puas \\
3 & Bitter/Sweet & 5 & 70 & Sangat puas \\
4 & Aftertaste & 3 & 60 & Cukup puas \\
5 & Fragrance/Aroma & 3 & 60 & Cukup puas \\
6 & Mouthfeel & 3 & 40 & Cukup puas \\
7 & Flavor & 3 & 40 & Cukup puas \\
8 & Overall & 3 & 40 & Cukup puas \\
9 & Balance & 2 & 50 & Tidak puas \\
10 & Salt/Acid & 1 & 60 & Sangat tidak puas \\
\hline
\end{tabular}

\subsubsection{Target}

Hasil pengolahan data mengenai target yang perlu dicapai oleh perusahaan dapat dilihat di Tabel 5.

Tabel 5. Target

\begin{tabular}{clcccc}
\hline No. & \multicolumn{1}{c}{ Atribut } & Produk A & Produk B & Target & Keterangan \\
\hline 1 & Clean Cups & 5 & 5 & 5 & Dipertahankan \\
2 & Bitter/Sweet & 5 & 5 & 5 & Dipertahankan \\
3 & Uniform Cups & 5 & 5 & 5 & Dipertahankan \\
4 & Balance & 2 & 2 & 2 & Dipertahankan \\
5 & Salt/Acid & 1 & 1 & 1 & Dipertahankan \\
6 & Aftertaste & 1 & 3 & 3 & Ditingkatkan \\
7 & Mouthfeel & 2 & 3 & 3 & Ditingkatkan \\
8 & Flavor & 2 & 3 & 3 & Ditingkatkan \\
9 & Fragrance/Aroma & 2 & 3 & 3 & Ditingkatkan \\
\hline
\end{tabular}




\begin{tabular}{llllll}
\hline 10 & Overall & 2 & 3 & 3 & Ditingkatkan \\
\hline
\end{tabular}

\subsubsection{Rasio Perbaikan}

Hasil pengolahan data mengenai tingkat perbaikan yang perlu dilakukan oleh perusahaan terhadap setiap atribut produk kopi premium dapat dilihat di Tabel 6.

Tabel 6. Rasio Perbaikan

\begin{tabular}{clcc}
\hline No. & \multicolumn{1}{c}{ Atribut } & Rasio Perbaikan & Keterangan \\
\hline 1 & Aftertaste & 3 & Perbaikan menyeluruh \\
2 & Mouthfeel & 1.5 & Perbaikan sedang \\
3 & Flavor & 1.5 & Perbaikan sedang \\
4 & Fragrance/Aroma & 1.5 & Perbaikan sedang \\
5 & Overall & 1.5 & Perbaikan sedang \\
6 & Salt/Acid & 1 & Tanpa perbaikan \\
7 & Balance & 1 & Tanpa perbaikan \\
8 & Clean Cups & 1 & Tanpa perbaikan \\
9 & Bitter/Sweet & 1 & Tanpa perbaikan \\
10 & Uniform Cups & 1 & Tanpa perbaikan \\
\hline
\end{tabular}

\subsubsection{Sales point}

Hasil pengolahan data mengenai titik penjualan setiap atribut produk kopi premium bagi konsumen dapat dilihat di Tabel 7.

Tabel 7. Sales Point

\begin{tabular}{clccc}
\hline No. & \multicolumn{1}{c}{ Atribut } & Sales Point & Persentase (\%) & Keterangan \\
\hline 1 & Flavor & 1.5 & 93.7 & Kuat \\
2 & Overall & 1.5 & 92.6 & Kuat \\
3 & Uniform Cups & 1.5 & 89.4 & Kuat \\
4 & Balance & 1.5 & 85.2 & Kuat \\
5 & Fragrance/Aroma & 1.5 & 83.2 & Kuat \\
6 & Clean Cups & 1.5 & 81.1 & Kuat \\
7 & Mouthfeel & 1.5 & 76.9 & Kuat \\
8 & Bitter/Sweet & 1.5 & 64.2 & Kuat \\
9 & Aftertaste & 1.5 & 51.5 & Kuat \\
10 & Salt/Acid & 1.5 & 37.9 & Kuat \\
\hline
\end{tabular}

\subsubsection{Raw weight dan normalized raw weight}

Hasil pengolahan data mengenai nilai bobot dan bobot normal atribut produk kopi premium dapat dilihat di Tabel 8.

Tabel 8. Raw Weight dan Normalized Raw Weight

\begin{tabular}{clccc}
\hline No. & \multicolumn{1}{c}{ Atribut } & Nilai Bobot & Nilai Bobot Normal & Prioritas \\
\hline 1 & Aftertaste & 13.5 & 0.15 & 1 \\
2 & Flavor & 11.25 & 0.13 & 2 \\
3 & Fragrance/Aroma & 11.25 & 0.13 & 2 \\
4 & Overall & 11.25 & 0.13 & 2 \\
5 & Mouthfeel & 9 & 0.10 & 3 \\
6 & Balance & 7.5 & 0.08 & 4 \\
7 & Clean Cups & 7.5 & 0.08 & 4 \\
8 & Uniform Cups & 7.5 & 0.08 & 4 \\
9 & Bitter/Sweet & 6 & 0.07 & 5 \\
10 & Salt/Acid & 4.5 & 0.05 & 6 \\
\hline
\end{tabular}

\subsection{Matriks respon teknis}


Dalam prosesnya, KTKMA tidak langsung menerima semua kebutuhan konsumen tersebut. KTKMA harus menyesuaikannya dengan kesanggupan dan standar yang telah ada dalam perusahaan. Hasil pembuatan respon teknis sesuai dengan studi pustaka dan diskusi dengan pemilik usaha dapat dilihat di Tabel 9.

Tabel 9. Respon Teknis Perusahaan

\begin{tabular}{cll}
\hline No. & \multicolumn{1}{c}{ Persyaratan Teknis } & \multicolumn{1}{c}{ Interpretasi } \\
\hline 1. & Penggunaan biji kopi robusta & $\begin{array}{l}\text { Menggunakan formula baru 100\% biji } \\
\text { kopi robusta }\end{array}$ \\
2. & Penerapan tahap sortasi biji kopi & $\begin{array}{l}\text { Memilih biji kopi sesuai standar } \\
\text { perusahaan }\end{array}$ \\
3. & $\begin{array}{l}\text { Perhatian terhadap suhu dan } \\
\text { durasi penyangraian }\end{array}$ & $\begin{array}{l}\text { Menggunakan mesin sangrai yang } \\
\text { dilengkapi kontrol suhu }\end{array}$ \\
\hline
\end{tabular}

\subsection{Matriks hubungan}

Hubungan yang kuat $(+9)$ ditandai dengan simbol $(\mathbf{O}$, hubungan sedang $(+3)$ ditandai dengan $(O)$, hubungan lemah $(+1)$ ditandai dengan $(\Delta$, dan tidak ada hubungan $(0)$ ditandai dengan simbol kosong (Wijaya, 2011). Semakin kuat suatu hubungan dalam matriks ini, maka semakin efektif pula suatu persyaratan teknis tersebut dalam memenuhi keinginan konsumen (Abuzid, 2017). Penentuan hubungan kedua komponen disusun berdasarkan studi pustaka dan diskusi dengan pemilik usaha. Hasil penentuan hubungan kedua komponen tersebut disajikan pada Gambar 1.

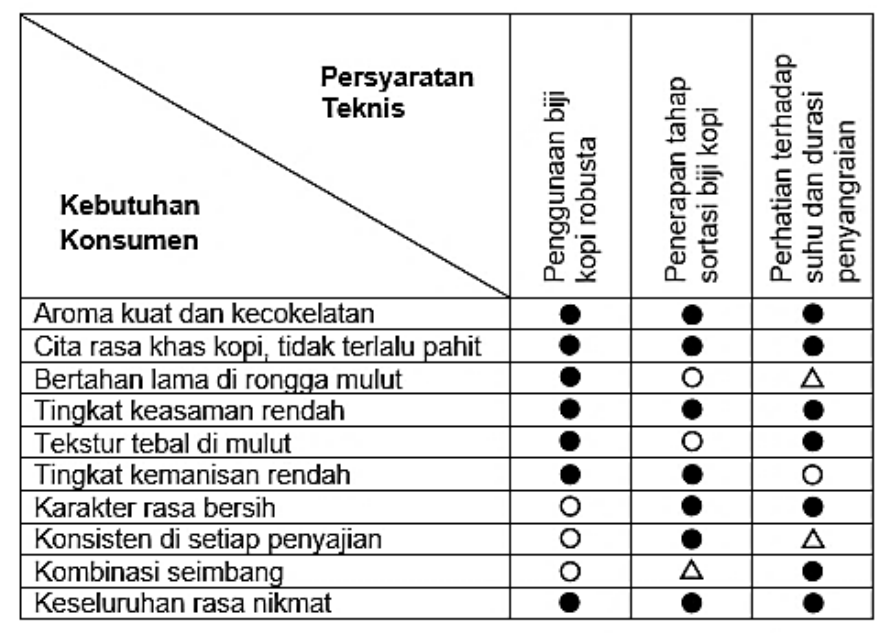

Gambar 1. Matriks Hubungan

\subsection{Matriks teknis}

Dalam membuat matrik teknis diperlukan data untuk mengisi kolom importance of technical, technical benchmarking, dan technical targets (Adriantantri, 2008). Data yang dibutuhkan diperoleh dari hasil perhitungan dan hasil survei yang saling berhubungan. Kolomkolom yang perlu diisi antara lain:

\subsubsection{Importance of technical}

Hasil pengolahan data mengenai bobot kepentingan persyaratan teknis beserta prioritasnya dapat di Tabel 10. Menurut Andriani, Choiri, dan Priharseno (2017), semakin tinggi nilai prioritas, maka semakin besar pula kontribusi suatu persyaratan teknis dalam memenuhi kepuasan konsumen.

Tabel 10. Importance of Technical

No. Persyaratan Teknis Bobot Kepentingan Prioritas




\begin{tabular}{llll}
\hline 1 & Penggunaan biji kopi robusta & 7.56 & 1 \\
2 & Penerapan tahap sortasi biji kopi & 6.86 & 2 \\
3 & Perhatian terhadap suhu dan & 6.74 & 3 \\
\hline
\end{tabular}

\subsubsection{Technical benchmarking}

Hasil pengolahan data mengenai nilai perbandingan performa persyaratan teknis antara prototipe kopi premium dan produk kopi pesaing dapat dilihat di Tabel 11.

Tabel 11. Technical Benchmarking

\begin{tabular}{clcc}
\hline No. & \multicolumn{1}{c}{ Persyaratan Teknis } & $\begin{array}{c}\text { Prototipe Kopi } \\
\text { Premium }\end{array}$ & $\begin{array}{c}\text { Kopi Robusta Fine } \\
\text { Dampit }\end{array}$ \\
\hline 1 & Penggunaan biji kopi robusta & 2.38 & 3.13 \\
2 & $\begin{array}{l}\text { Penerapan tahap sortasi biji } \\
\text { kopi }\end{array}$ & 2.99 & 3.50 \\
3 & $\begin{array}{l}\text { Perhatian terhadap suhu dan } \\
\text { durasi penyangraian }\end{array}$ & 2.43 & 2.99 \\
\hline
\end{tabular}

\subsubsection{Technical targets}

Hasil pengolahan data mengenai nilai target persyaratan teknis yang harus dicapai oleh KTKMA agar dapat bersaing dengan kompetitor dapat dilihat di Tabel 12.

Tabel 12. Technical Targets

\begin{tabular}{clccc}
\hline No. & Persyaratan Teknis & \multicolumn{1}{c}{ Nilai } & Keterangan \\
\hline 1 & $\begin{array}{l}\text { Penggunaan biji kopi } \\
\text { robusta }\end{array}$ & 2.38 & 3.13 & Ditingkatkan \\
2 & $\begin{array}{l}\text { Penerapan tahap sortasi } \\
\text { biji kopi }\end{array}$ & 2.99 & 3.50 & Ditingkatkan \\
3 & $\begin{array}{l}\text { Perhatian terhadap suhu } \\
\text { dan durasi penyangraian }\end{array}$ & 2.43 & 2.99 & Ditingkatkan \\
\hline
\end{tabular}

\subsection{Matriks korelasi teknis}

Persyaratan teknis yang teridentifikasi memiliki hubungan dan saling mendukung, maka keduanya ditandai dengan simbol hubungan positif sedang $(+)$ atau hubungan positif kuat $(++)$. Sementara itu, apabila persyaratan respon teknis diidentifikasi memiliki hubungan dan saling berlawanan, maka keduanya ditandai dengan simbol hubungan negatif sedang (-) atau hubungan negatif kuat (--) (Prasad, 1998). Hasil penentuan korelasi teknis dapat dilihat di Gambar 2.

\begin{tabular}{|l|l|c|c|}
\hline \multicolumn{1}{|c|}{$\begin{array}{c}\text { Persyaratan } \\
\text { Teknis }\end{array}$} & $\begin{array}{c}\text { Penggunaan } \\
\text { biji kopi } \\
\text { robusta }\end{array}$ & $\begin{array}{c}\text { Penerapan } \\
\text { tahap sortasi } \\
\text { biji kopi }\end{array}$ & $\begin{array}{c}\text { Perhatiap } \\
\text { terhadap suhu } \\
\text { dan durasi } \\
\text { penyangraian } \\
\text { Teknis }\end{array}$ \\
\hline $\begin{array}{l}\text { Penggunaan biji kopi } \\
\text { robusta }\end{array}$ & & + & ++ \\
\hline $\begin{array}{l}\text { Penerapan tahap sortasi } \\
\text { biji kopi }\end{array}$ & & & \\
\hline $\begin{array}{l}\text { Perhatiap terhadap suhu } \\
\text { dan durasi penyangraian }\end{array}$ & & & \\
\hline
\end{tabular}

Gambar 2. Matriks Korelasi Teknis

\subsection{Penyusunan House of Quality}


Semua data hasil pengolahan di fase pertama kemudian disusun menjadi satu membentuk bangunan rumah. HoQ terdiri dari enam buah matriks. Hasil penyusunan $\mathrm{HoQ}$ dapat dilihat di Gambar 3.
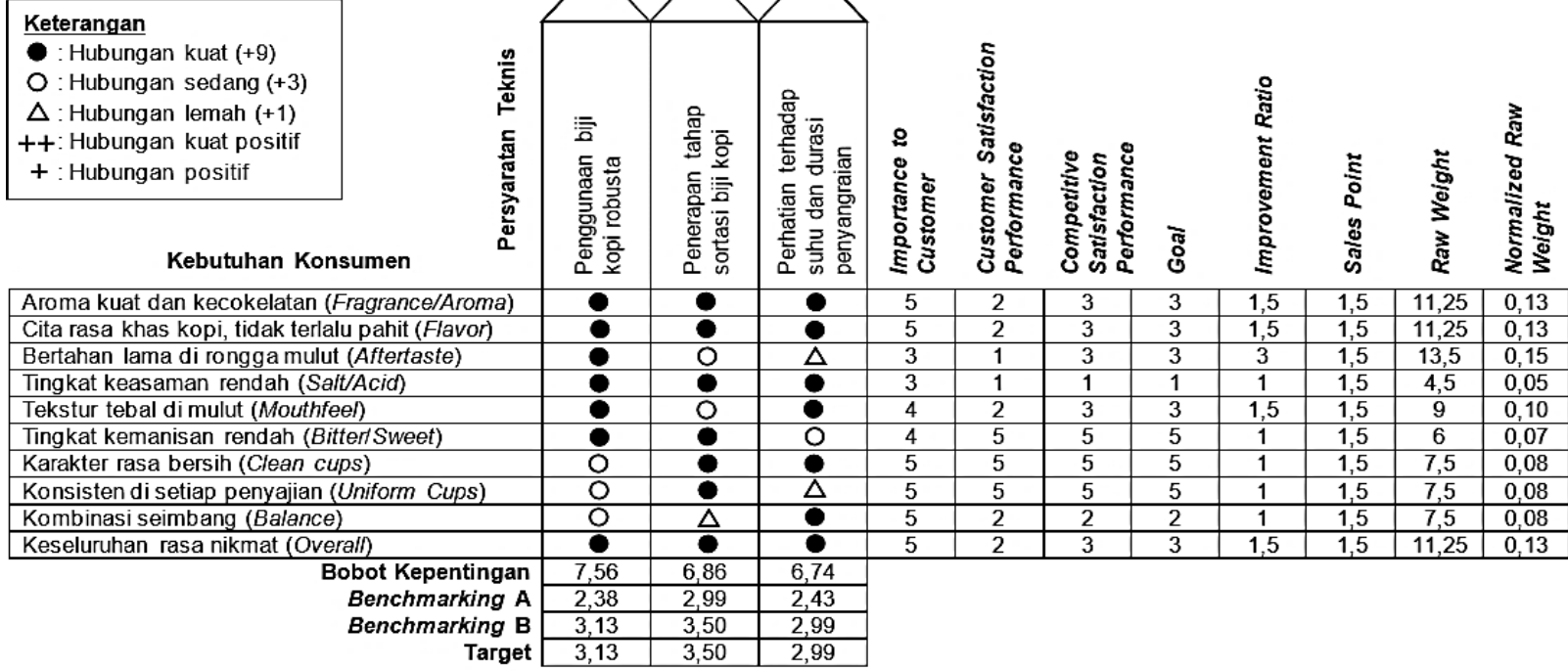

Gambar 3. House of Quality

\section{Fase II: Product Design}

Matriks desain produk dapat dilihat di Gambar 4.

\begin{tabular}{|c|c|c|c|c|}
\hline \multirow[b]{2}{*}{$\begin{array}{l}\text { Persyaratan } \\
\text { Teknis }\end{array}$} & \multicolumn{3}{|c|}{ Spesifikasi Komponen } & \multirow[b]{2}{*}{ 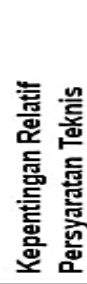 } \\
\hline & 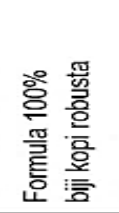 & 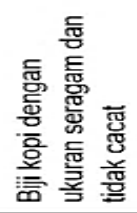 & 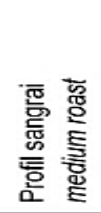 & \\
\hline $\begin{array}{l}\text { Penggunaan biji kopi } \\
\text { robusta }\end{array}$ & - & 0 & 0 & 7,56 \\
\hline $\begin{array}{l}\text { Penerapan tahap sortasi } \\
\text { biji kopi }\end{array}$ & - & - & $\Delta$ & 6,86 \\
\hline $\begin{array}{l}\text { Perhatian terhadap suhu } \\
\text { dan durasi penyangraian }\end{array}$ & $\bullet$ & $\Delta$ & $\bullet$ & 6,74 \\
\hline $\begin{array}{l}\text { Kepentingan Relatif } \\
\text { Spesifikasi Komponen }\end{array}$ & 190,44 & 91,16 & 90,20 & \\
\hline Prioritas & 1 & 2 & 3 & \\
\hline
\end{tabular}

Gambar 4. Matriks Desain Produk

Di fase kedua, diperoleh spesifikasi komponen hasil penerjemahan dari persyaratan teknis, antara lain formulasi $100 \%$ biji kopi robusta (prioritas 1), biji kopi dengan ukuran seragam dan tidak cacat (prioritas 2 ), dan profil sangrai medium roast (prioritas 3 ). Hasil yang diperoleh dari fase ini adalah prioritas spesifikasi komponen berdasarkan kemampuannya dalam memenuhi kebutuhan konsumen.

\section{Fase III: Process Planning}

Di fase yang ketiga, rencana proses yang dibutuhkan untuk mencapai spesifikasi komponen yang telah ditetapkan disusun berdasarkan diskusi dengan pemilik usaha dan studi pustaka. Rencana proses produksi kopi premium diawali dengan pemilihan formula biji kopi 
robusta $100 \%$ (prioritas 1), kemudian penyortasian biji kopi (prioritas 2), lalu penyangraian dengan suhu $130^{\circ} \mathrm{C}$ hingga mencapai first crack (prioritas 3), pengeluaran biji kopi dari mesin sangrai (prioritas 5), pendinginan biji kopi hingga suhu ruang (prioiritas 4), dan diakhir dengan pengemasan dengan kemasan one-way valve (prioritas 4). Matriks rencana proses dapat dilihat di Gambar 5.

\begin{tabular}{|c|c|c|c|c|c|c|c|}
\hline \multirow[b]{2}{*}{$\begin{array}{l}\text { Spesifikasi } \\
\text { Komponen }\end{array}$} & \multicolumn{6}{|c|}{ Rencana Proses } & \multirow[b]{2}{*}{ 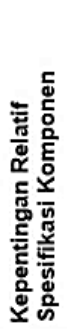 } \\
\hline & 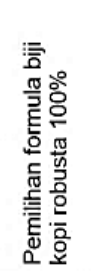 & 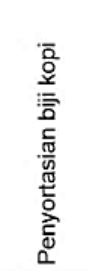 & 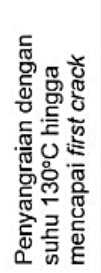 & 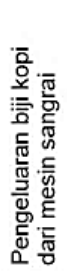 & 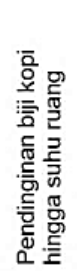 & 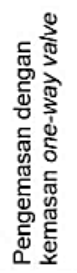 & \\
\hline $\begin{array}{l}\text { Formula } 100 \% \text { biji kopi } \\
\text { robusta }\end{array}$ & - & 0 & 0 & & & & 190,44 \\
\hline $\begin{array}{l}\text { Biji kopi dengan ukuran } \\
\text { seragam dan tidak cacat }\end{array}$ & $\bullet$ & $\bullet$ & O & & & & 91,16 \\
\hline Profil sangrai medium roast & $\bullet$ & 0 & - & & 0 & 0 & 90,20 \\
\hline $\begin{array}{l}\text { Kepentingan Relatif } \\
\text { Rencana Proses }\end{array}$ & 3360,16 & 1662,36 & 1656,60 & 0 & 90,20 & 90,20 & \\
\hline Prioritas & 1 & 2 & 3 & 5 & 4 & 4 & \\
\hline
\end{tabular}

Gambar 5. Matriks Rencana Proses

\section{Fase IV: Production Planning}

$\mathrm{Di}$ fase yang terakhir, dilakukan penentuan persyaratan produksi untuk dapat menjalankan rencana proses dengan baik hingga tercapainya spesifikasi komponen dan memenuhi kebutuhan konsumen. Persyaratan produksi disusun berdasarkan Penentuan hubungan kedua komponen disusun berdasarkan studi pustaka dan diskusi dengan pemilik usaha. Matriks persyaratan produksi dapat dilihat di Gambar 6.

\begin{tabular}{|c|c|c|c|c|c|c|}
\hline \multirow[b]{2}{*}{ Rencana Proses } & \multicolumn{5}{|c|}{ Persyaratan Produksi } & \multirow[b]{2}{*}{ 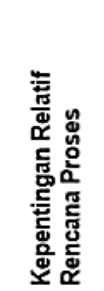 } \\
\hline & 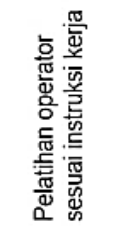 & 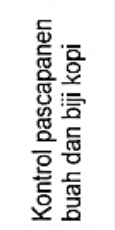 & 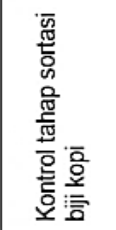 & 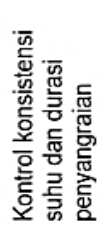 & 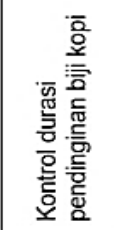 & \\
\hline $\begin{array}{l}\text { Pemilihan formula biji kopi } \\
\text { robusta } 100 \%\end{array}$ & - & - & 0 & & & 3360,16 \\
\hline Penyortasian biji kopi & $\bullet$ & - & $\bullet$ & & & 1662,36 \\
\hline $\begin{array}{l}\text { Penyangraian suhu } 130^{\circ} \mathrm{C} \\
\text { hingga mencapai first crack }\end{array}$ & 0 & & $\Delta$ & $\bullet$ & $\Delta$ & 1656,60 \\
\hline $\begin{array}{l}\text { Pendinginan biji kopi hingga } \\
\text { suhu ruang }\end{array}$ & $\bullet$ & & & 0 & - & 90,20 \\
\hline $\begin{array}{l}\text { Pengemasan dengan } \\
\text { kemasan one-way valve }\end{array}$ & $\bullet$ & & & & $\Delta$ & 90,20 \\
\hline $\begin{array}{l}\text { Kepentingan Relatif } \\
\text { Persyaratan Produksi }\end{array}$ & 61735,68 & 45202,68 & 26698,32 & 15180 & 25558,60 & \\
\hline Prioritas & 1 & 2 & 3 & 5 & 4 & \\
\hline
\end{tabular}

Gambar 6. Matriks Persyaratan Produksi

Persyaratan produksi hasil terjemahan dari rencana proses, antara lain: pelatihan operator sesuai instruksi kerja (prioritas 1), kontrol pascapanen buah dan biji kopi (prioritas 2), kontrol tahap sortasi biji kopi (prioritas 3), kontrol konsistensi suhu dan durasi penyangraian (prioritas 5), dan yang terakhir adalah kontrol durasi pendinginan biji kopi (prioritas 4).

\section{Rekomendasi Perbaikan}

Berdasarkan hasil dari fase keempat QFD, terdapat beberapa persyaratan produksi yang harus diperhatikan dan dipenuhi oleh KTKMA untuk dapat memenuhi kebutuhan konsumen. Dari persyaratan-persyaratan produksi tersebut lahirlah rekomendasi perbaikan untuk memperoleh hasil kopi premium yang lebih baik. Rekomendasi perbaikan disesuaikan 
berdasarkan kondisi yang terjadi di proses produksi perusahaan. KTKMA dapat mempertimbangkan masukan yang ada sesuai dengan kesanggupan perusahaan. Lebih jelasnya, rekomendasi perbaikan untuk perusahaan dijabarkan di Tabel 13.

\section{Tabel 13. Rekomendasi Perbaikan}

\begin{tabular}{|c|c|c|}
\hline $\begin{array}{l}\text { Persyaratan } \\
\text { Produksi }\end{array}$ & Kondisi Produksi Perusahaan & Rekomendasi Perbaikan \\
\hline \multirow[t]{5}{*}{$\begin{array}{l}\text { Kontrol } \\
\text { pascapanen }\end{array}$} & npur berwarna & $\begin{array}{l}\text { Kontrol hanya petik buah kopi yang berwarna } \\
\text { merah (Afriliana, 2018) }\end{array}$ \\
\hline & proses pascapanen & Portahankan nrocec naccananon natural/dru \\
\hline & $\begin{array}{l}\text { Penjemuran buah kopi selama } 21 \text { hari } \\
\text { atau lebih (waktu tidak terkontrol) hingga } \\
\text { diperoleh biji kopi dengan kadar air yang } \\
\text { tidak terkontrol }\end{array}$ & $\begin{array}{l}\text { Kontrol penjemuran buah kopi selama } 21 \text { hari } \\
\text { sampai maksimal } 28 \text { hari hingga diperoleh biji } \\
\text { kopi dengan kadar air } 11-12 \% \text { (Afriliana, } 2018 \text { ) }\end{array}$ \\
\hline & $\begin{array}{l}\text { aban }(\mathrm{RH}) \text { dan suhu } \\
\text { nan biji kopi tidak }\end{array}$ & $\begin{array}{l}\text { Kontrol ruang penyimpanan biji kopi dengan } \mathrm{RH} \\
50-70 \% \text { dan suhu sekitar } 26^{\circ} \mathrm{C} \text { (Bucheli et al., } \\
1998)\end{array}$ \\
\hline & & $\begin{array}{l}\text { Kontrol masa simpan biji kopi maksimal } 3 \text { bulan } \\
\text { (Bucheli et al., 1998) }\end{array}$ \\
\hline Kontrol sortasi & n sortasi biji kopi berdasarkan & $\begin{array}{l}\text { Kontrol sortasi biji kopi sesuai dengan SNI 01- } \\
2907: 2008 \text { (BSN, 2008) }\end{array}$ \\
\hline $\begin{array}{l}\text { Kontrol } \\
\text { penyangraian }\end{array}$ & $\begin{array}{l}\text { Suhu dan durasi optimal penyangraian } \\
\text { untuk profil medium roast masih belum } \\
\text { diketahui }\end{array}$ & $\begin{array}{l}\text { Penyangraian dengan suhu } 180^{\circ} \mathrm{C} \text { selama } 10 \\
\text { menit (Dharmawan, Cahyo, dan Widyotomo, } \\
\text { 2018) atau dapat dilakukan uii coba sendiri }\end{array}$ \\
\hline & $\begin{array}{l}\text { laksimal mesin sangrai hanya } \\
\text { bai } 130^{\circ} \mathrm{C}\end{array}$ & $\begin{array}{l}\text { Ganti kompor mesin sangrai dengan kompor } \\
\text { bertekanan tinggi }\end{array}$ \\
\hline $\begin{array}{l}\text { Kontrol } \\
\text { pendinginan }\end{array}$ & $\begin{array}{l}\text { Durasi pendinginan biji kopi hasil sangrai } \\
\text { belum terkontrol }\end{array}$ & $\begin{array}{l}\text { Lakukan uji coba terhadap durasi pendinginan } \\
\text { yang paling singkat sebagai kontrol }\end{array}$ \\
\hline
\end{tabular}

\section{SIMPULAN}

Kesimpulan yang dapat diambil dari penelitian mengenai pengembangan produk kopi premium ini adalah atribut kualitas yang dibutuhkan oleh konsumen untuk produk kopi premium, yakni aroma khas kopi yang kuat dan sedikit terasa kecokelatan (fragrance/aroma), cita rasa khas kopi yang tidak terlalu pahit (flavor), rasa kopi yang bertahan lama di rongga mulut (aftertaste), tingkat keasaman rendah (salt/acid), tekstur terasa tebal di rongga mulut (mouthfeel), tingkat kemanisan rendah (bitter/sweet), konsistensi setiap sajian (uniform cups), karakter bersih (clean cups), kombinasi yang seimbang (balance), dan keseluruhan rasa kopi yang nikmat (overall). Melalui analisis dengan metode Quality Function Deployment diketahui bahwa untuk memenuhi kebutuhan konsumen, Kelompok Tani Kopi Makmur Abadi perlu melakukan pelatihan operator sesuai instruksi kerja, kontrol pascapanen buah dan biji kopi, kontrol tahap sortasi biji kopi, kontrol konsistensi suhu dan durasi penyangraian, dan kontrol durasi pendinginan biji kopi.

\section{DAFTAR PUSTAKA}

Abuzid, H. F. T. (2017). Applying QFD Tools for Quality Improvements in Curriculum Design and Teaching Strategies to Meet with the Customer (Learner) Needs. Journal of Engineering and Applied Sciences, 12(3), 684-690. https://doi.org/10.36478/jeasci.2017.684.690

Adriantantri, E. (2008). Aplikasi Metode Quality Function Deployment (QFD) dalam Usaha Memenuhi Kepuasan Pelanggan terhadap Produk Aqua Gelas $240 \mathrm{~mL}$ pada PT. Tirta Investama Pandaan. Prosiding Seminar Nasional Teknoin 2008 Bidang Teknik Industri, 37-44. Prosiding Seminar Nasional Teknoin.

Afriliana, A. (2018). Teknologi Pengolahan Kopi Terkini. Yogyakarta: Deepublish.

Andriani, A. N. D. (2017). Pengendalian Kualitas Kopi Bubuk Banyuatis Reguler Sesuai 
Harapan Konsumen (Kasus Pada Pengolahan Kopi Bubuk Tradisional di Kabupaten Buleleng, Bali). Universitas Brawijaya.

Andriani, D. P., Choiri, M., \& Priharseno, D. (2017). Aplikasi Quality Function Deployment untuk Redesign Kontainer Penyimpanan pada Industri Kemasan Kaleng. Jurnal Teknik Industri, 18(2), 176. https://doi.org/10.22219/JTIUMM.Vol18.No2.176-190

BSN. Biji Kopi. , Pub. L. No. SNI 01-2907:2008, 12 (2008).

Bucheli, P., Meyer, I., Pittet, A., Vuataz, G., \& Viani, R. (1998). Industrial Storage of Green Robusta Coffee under Tropical Conditions and Its Impact on Raw Material Quality and Ochratoxin A Content. J. Agric. Food Chem., 46(11), 4507-4511. https://doi.org/10.1021/jf980468+

Dharmawan, A., Cahyo, F., \& Widyotomo, S. (2018). Determining Optimum Point of Robusta Coffee Bean Roasting Process for Taste Consistency. Pelita Perkebunan, 34(1), 59-65.

Gumilar, I. (2007). Metode Riset untuk Bisnis dan Manajemen. Bandung: Utamalab.

Jensen, F. (2017). Quality Function Deployment: The Evolved 4-Phase Model. Morrisville: Lulu Press.

Nevita, A. P., \& Andi, J. (2017). Perancangan dan Pengembangan Produk Kopi untuk Meningkatkan Kualitas Pemasaran dengan Berorientasi pada Pelanggan. Prosiding Seminar Nasional Inovasi Dan Aplikasi Teknologi Industri. Retrieved from http://ejournal.itn.ac.id/index.php/seniati/issue/view/83

Patro, C. S., \& M.V.Prasad. (2013). A Study on Implementation of Quality Function Deployment Technique in Product Design Stage. International Journal of Management Research and Review, 3(6), 2966-2974.

Prasad, B. (1998). Review of QFD and Related Deployment Techniques. Journal of Manufacturing Systems, 17(3), 221-234. https://doi.org/10.1016/S02786125(98)80063-0

R, A. P., Effendi, U., \& Effendi, M. (2015). Analisis Perencanaan Strategi Peningkatan Kualitas Pelayanan Konsumen dengan Metode Quality Function Deployment. Jurnal Industria, 4(1), 41-52.

Retnowati, N. (2012). Implementasi Metode Quality Function Deployment (Fase I) pada Produk Kopi Bubuk "Gunung ljen Robusta" (Studi Kasus pada PT. Perkebunan Nusantara XII). Jurnal IImiah Inovasi, 12(2), 111-117. https://doi.org/10.25047/jii.v12i2.332

Siyoto, S., \& Sodik, M. A. (2015). Dasar Metodologi Peneliitian (Cetakan 1; Ayup, Ed.). Yogyakarta: Literasi Media Publishing.

Syah, H., Yusmanizar, \& Maulana, O. (2013). Karakteristik Fisik Bubuk Kopi Arabika Hasil Penggilingan Mekanis dengan Penambahan Jagung dan Beras Ketan. Jurnal Teknologi Dan Industri Pertanian Indonesia, 5(1), 32-37. https://doi.org/10.17969/jtipi.v5i1.1000

Trinafianita, E., \& Widyaningsih, T. D. (2018). Kajian Perlakuan Awal Bahan dan Proporsi Penyeduuhan Kopi Bubuk: Air Pada Proses Pembuatan Kopi Dari Kulit Buah Kopi Arabika (Coffea Arabica L) Lereng Bromo. Jurnal Pangan Dan Agroindustri, 6(4), 5969. https://doi.org/10.21776/ub.jpa.2018.006.04.7

UCDA. (2010). Robusta Cupping Protocols. Kampala.

Umar, H. (2000). Riset Pemasaran dan Perilaku Konsumen. Jakarta: Gramedia Pustaka Utama.

Zare Mehrjerdi, Y. (2010). Quality Function Deployment and Its Extensions. International Journal of Quality \& Reliability Management, 27(6), 616-640. https://doi.org/10.1108/02656711011054524 